\title{
Educação e expressividade no pensamento estético de Theodor W. Adorno ${ }^{1}$
}

\begin{abstract}
Resumo
No âmbito de uma filosofia da educação, cabe-nos colocar uma questão: como pensar o conceito de educação na perspectiva da expressividade estética da arte? No presente artigo, propomo-nos a pensar a educação vinculada aos aspectos da crítica da razão instrumental, considerá-la, portanto, a partir de seus desdobramentos formativos. Este texto tem como objetivo problematizar a racionalidade da educação contemporânea, a partir de alguns aspectos fundamentais do pensamento estético de Theodor W. Adorno. O que significa possibilitar a capacidade de abertura e de sensibilidade da ação educativa para compreender os desafios apontados pelo sentido da expressividade estética na formação cultural contemporânea.
\end{abstract}

Palavras-chave: Educação; Formação cultural; Emancipação; Theodor W. Adorno.

\author{
Alex Sander da Silva \\ Doutor em Educação pela \\ Pontifícia Universidade Católica \\ do Rio Grande do Sul - PUCRS - \\ Brasil \\ alexsanders@unesc.net
}

\section{Para citar este artigo:}

SILVA, Alex Sander da. Educação e expressividade no pensamento estético de Theodor W. Adorno. Revista Linhas. Florianópolis, v. 16, n. 31, p. 216 - 229, maio/ago. 2015.

\section{DOI: $10.5965 / 1984723816312015216$}

http://dx.doi.org/10.5965/1984723816312015216

\footnotetext{
${ }^{1}$ Este artigo foi financiado pelo edital 59/2014 do Programa de Grupos de Pesquisa da PROPEX/UNESC 20142016.
} 


\title{
Education and expressiveness in the aesthetic thinking of Theodor W. Adorno
}

\begin{abstract}
As part of a philosophy of education, we must ask a question: How do think the concept of education in the perspective of aesthetic expressiveness of the art? In these terms, we intend to consider education linked to aspects of critique of instrumental reason. This text has the basic point, questioning the rationality of contemporary education, from some fundamental aspects of aesthetic thought of Theodor W. Adorno. This means the ability to enable openness and sensitivity of educational action to understand the challenges identified by the sense of aesthetic expression in contemporary cultural formation.
\end{abstract}

Keywords: Education; Training cultural; Emancipation; Theodor W. Adorno. 


\section{Introdução}

Ao pensarmos sobre aquilo que é distintivo da ação educativa, não nos propomos a compreender somente sua dimensão didático-metodológica, ou seja, sua racionalidade instrumental, mas, sobretudo, o modo como o ato educativo se relaciona com uma racionalidade crítico-reflexiva. Desse modo, pensar sobre a prática educativa significa mobilizar a reflexão sobre o sentido "do educar", buscando compreender sua racionalidade formativa e sensível diante dos acontecimentos do mundo contemporâneo.

Cabe-nos, então, colocar uma questão: como pensar o conceito de educação na perspectiva da formação cultural contemporânea? Nesses termos, buscar uma resposta razoável significaria pensar a educação vinculada aos aspectos da formação cultural contemporânea, em especial, em suas relações com as linguagens das obras de arte em sua expressividade estética atual ou, se quisermos considerar a educação a partir dos seus desdobramentos estético-formativos na prática pedagógica.

Assim, neste texto, pretendemos problematizar a racionalidade da educação contemporânea, a partir de alguns aspectos fundamentais do pensamento estético de Theodor W. Adorno, tendo em vista a sensibilização da ação educativa para a compreensão dos desafios apontados pelo sentido da expressividade estética na formação cultural na obra de arte.

Para tanto, primeiramente, apresentamos uma maneira de entender a condição da educação, isto é, associada a uma profunda danificação da vida, tal como nos termos em que a danificação da vida é concebida por Adorno, em sua Minima Moralia (1993). Em seguida, procuraremos analisar em que medida a educação ainda é um recurso fundamental para uma formação cultural, e quais os limites da educação como recurso para uma formação cultural no horizonte do pensamento estético de Adorno. 


\section{A vida capturada e a educação danificada: sintomas (de)formativos da sociedade contemporânea}

Diferentes acontecimentos, como guerras, sequestros, estupros, violências físicas e simbólicas de todos os gêneros, ao lado de calamidades socioambientais, têm exposto a humanidade às mais cruéis vivências e provações. Dentre esses desastres de enormes proporções, não podemos nos esquecer daqueles cuja causa é a expropriação desmesurada dos bens culturais e dos direitos formativos das pessoas, associados à ganância e negligência de toda ordem.

O cenário do século XXI delineia ares de um contínuo desencantamento, no qual a racionalidade meramente instrumental lograria êxito em todos os terrenos da vida humana, particularmente, no âmbito econômico. Mas a confiança e o otimismo que animavam os rumos do mercado econômico foram substituídos pela dúvida e pelas incertezas de uma crise de caráter global. Isto envolve reconhecer, atualmente, que a crise (econômica, moral) vem colocando sob nova suspeita os rumos da própria humanidade como um mundo altamente racionalizado.

Este mundo racionalizado ${ }^{2}$, ao revelar suas inúmeras crises políticas, econômicas e socioculturais, tem gerado insegurança a homens e mulheres, idosos, jovens e crianças de todas as partes do globo. Os processos de desenvolvimento científico e tecnológico, obliterados pela razão instrumental, têm levado a termo a própria racionalização da vida. Trata-se, aqui, portanto, de colocar os efeitos da própria racionalidade instrumental nos contornos da vida cotidiana sob o crivo da reflexão crítica.

Neste horizonte, na Mínima Moralia (1993), o filósofo Theodor W. Adorno nos oferece um desafio, incômodo e provocador: o de desvelar as máscaras sob as quais a sociedade se ocupa de encobrir a danificação da vida. É nesse sentido que Adorno insiste na denúncia da razão instrumental como lugar no qual se confundem a racionalidade dos

\footnotetext{
${ }^{2}$ Adorno e Horkheimer, ao tomarem o processo de racionalização da cultura ocidental (Iluminismo) como um processo de esclarecimento pela razão, denunciam o caráter essencialmente dominador que este processo assume. Ao invés de proporcionar uma vida mais digna aos seres humanos (o que, aliás, deveria ser seu objetivo principal), o esclarecimento acaba por instrumentalizar as próprias relações humanas.
} 
meios técnicos e a racionalidade da dominação. Com base nesta convicção, procura evidenciar a existência da suspeita em relação ao próprio pensamento filosófico, observável desde o trato mais simples entre as pessoas, até a complexidade do pensamento.

O caráter fragmentário dos textos da Mínima Moralia busca mostrar, nas particularidades da vida dos indivíduos, algo que ultrapasse o imediato, entende-o como tarefa de uma filosofia que não se acomoda na totalidade aparente, trazendo à tona, assim, aquilo para além das aparências. Nas palavras de Duarte,

[o] principal escopo é uma reaproximação entre a filosofia e a mais crua imediatidade da vida prosaica na fase tardia do capitalismo mundial, para a realização da qual o seu autor empreende simultaneamente um implacável acerto de contas com uma representativa tradição filosófica, protagonizada por Kant, Hegel, Marx, Nietzsche, Schopenhauer e Freud, dentre outros. (DUARTE, 1997b, p. 146)

Assim, já de antemão, sabida sua incompletude, o todo social é entendido a partir de diferentes pontos de vista, principalmente, no qual ele se manifesta mais intensamente, ou seja, no particular. Nele, no particular, residiria então a possibilidade de clarificar os imperativos da sociedade capitalista, na busca de uma totalidade que não se deixa perceber, pois já se dissolveu na fragmentação da vida danificada.

Nas instâncias que compõem esta sociedade, a totalidade danificada se realiza, ainda que disfarçada, ainda que apresentada sob a forma de aparência e de algo imediato. Por isso, de modo algum, é positiva a maneira como o particular deve ser enfrentado. O particular deve ser "revirado", "remexido", até que nele se encontrem os indícios de uma ordem superior, instalada nos pormenores da vida dos indivíduos.

Nesses termos, a Mínima Moralia se apresenta como metáfora para o estado de capitalismo monopolista, radicalizado nos monopólios da especulação do capital financeiro internacional. No capitalismo monopolista, a indústria cultural ganhou ainda mais poder, fazendo com que os sujeitos, que continuam sendo apêndices da maquinaria 
tecnológica, se tornem cada vez mais parecidos com ela. Esses e outros temas abordados por Adorno apontam para a aguda situação da vida danificada do sujeito no capitalismo contemporâneo.

No mundo do capital, a vida adquire um caráter pálido, prejudicado ou, como afirma o próprio Adorno:

Aquilo que "vida" significava outrora para os filósofos passou a fazer parte da esfera privada e, mais tarde ainda, da esfera do mero consumo, que o processo de produção material arrasta consigo como um apêndice sem autonomia e sem substância própria. Quem quiser saber a verdade acerca da vida imediata tem que investigar sua configuração alienada, investigar os poderes objetivos que determinam a existência individual no mais recôndito dela. (ADORNO, 1993, p. 7)

A configuração alienada que a vida assume contemporaneamente não se distancia da concepção conforme a qual a racionalidade instrumental está enraizada nos recônditos espaços da vida humana, ocultando-se daquilo que parece ser dela. Os argumentos se convertem em algo que mostra a modelagem de uma subjetividade moldada e absorvida pela totalidade social capitalista. Ou seja, compreendendo que a vida esteja danificada no sentido da alienação do indivíduo nessa totalidade.

A ideia de uma vida alienada e danificada aparece para Adorno como o resultado do condicionamento do sujeito absorvido pela totalidade social dominante. O que caracterizaria a vida dos indivíduos como coerção funcional relaciona-se a uma circunstância em que o membro particular da espécie humana se vê condicionado por uma rede funcional do sistema em que está inserido. O momento mais elevado desse poder sobre a vida humana pode ser expresso pelo poder adquirido pelo dinheiro, pela propriedade privada.

Segundo Marx, na sociedade capitalista "cada produto é uma isca com a qual se quer atrair o ser dos outros, seu dinheiro; toda necessidade real ou possível é uma fraqueza que arrastará as moscas ao melado - exploração universal da essência humana 
coletiva do homem..." (MARX, 1987, p. 182). O poder do dinheiro expressa o poder que o sujeito não mais tem sobre sua própria vida: "O dinheiro é a capacidade alienada da humanidade" (Ibid., p. 196).

Nessa lógica, a educação é também vítima desse processo de dominação, ao se transformar em mero dispositivo da alienação ideológica no capitalismo. Na sociedade regida pela lógica da produção e do consumo, a realização do trabalho é sua objetificação, ou seja, o sujeito transformador e a natureza a ser transformada são coisificados. É nesse sentido que a realização do trabalho é a negação do ser humano, tanto em sua universalidade, quanto em sua singularidade.

Segundo Marx (1987), a alienação é a expressão de uma inversão no relacionamento do ser humano com o produto e com ele mesmo. Não insistiremos nesse debate, mas é interessante notar que as razões da permanência da alienação são numerosas, e podem ser procuradas no esfacelamento dos indivíduos na expressão ideológica do próprio capitalismo.

Porém, aqui, nos interessa explorar as marcas de uma forma de resistência a essa lógica da alienação social no âmbito da educação.

\section{Educação e expressividade estética: possibilidades de resistência crítica para a formação cultural}

O percurso feito até aqui nos permitiu um breve levantamento de algumas especificidades das dimensões crítico-dialéticas do pensamento de Adorno, sobretudo, no que diz respeito a uma certa ideia de racionalidade instrumentalizada e suas consequências para a vida cotidiana. Agora, resta-nos estabelecer conexões entre os elementos dessa crítica com sua teoria estética, e examinar as possibilidades daí decorrentes para a emancipação contemporânea. Nisso, a pergunta: por que associar a questão da expressividade estética com a educação? A experiência estética possibilita a aproximação entre a educação e uma formação cultural para a emancipação? Se sim, o que isso significaria? 
Adorno, ao contrário de um resignado pessimismo, não hesita em considerar que, se não modificadas as condições objetivas, a lacuna entre as pretensões formativas e suas realizações propriamente ditas sempre existirá. Disto resulta que a educação tem de levar a cabo a proposta desestruturadora da totalidade social, o que não significa superestimá-la, mas sim corresponde à necessidade de compreender seu papel de resistência e crítica.

Em primeiro lugar, queremos dizer que a experiência e a expressão estética desafiam o sentido da educação para a emancipação. Desse modo, a racionalidade educativa passa a ser compreendida não somente pela razão instrumental, mas também por meio da noção de uma racionalidade estético-formativa. Logo, se recuperarmos o sentido da expressividade estética, podemos considerar que os próprios caracteres da educação são constituídos por elementos estéticos. Ora, a educação seria então também algo da ordem estético expressiva.

Em sua Teoria estética (1992), Adorno procurou compreender o movimento de constituição e de desdobramento da arte, a partir de vínculos contraditórios entre diversos polos: o indivíduo e a sociedade, a arte e a cultura de massa, a forma e o conteúdo, o belo artístico e o belo natural, entre outros. O conteúdo da arte mantém, nessa análise, uma instância inalcançável para a racionalidade instrumental.

Nessa perspectiva, a chave interpretativa adorniana encontra-se no conceito de mímesis, entendida não como mera imitação ou ajuste do pensamento a um modelo de racionalidade hegemônico. Em Adorno, a experiência estética reside na exposição do sujeito à própria experiência mimética autêntica. Os momentos da mímesis não se reduzem a cópias ou à imitação, porque associados ao regresso do irracional como racionalidade completa.

A mímesis traduz um novo significado do estético que se amplia, inclusive na própria obra de arte. Ela carrega duas tarefas importantes: primeira, conservar a imagem do seu objetivo obstruída pela racionalidade; segunda, convencer o estado de coisas existentes de sua irracionalidade, de sua absurdidade (ADORNO, 1992, p. 68), e expor aquilo que foi reprimido na natureza por meio da arte. 
Para Jimenez (1977, p. 178-179), "a antítese do mimético e do construído, aparente na estrutura, designa a oposição do momento de irracionalidade ao momento de racionalidade, pecado original da arte". O conceito mimético consiste no préespiritual; já o construído, vem a ser trabalho do espírito. A mímesis é, portanto, a força da expressividade da racionalidade, sobretudo, daquilo que ela própria, no mundo administrado, insiste em esquecer.

Adorno considera que a obra de arte é detentora de sua verdade somente no momento em que ultrapassa o que é simplesmente representado no conceito. No deslizamento interior, na sua impossibilidade de coincidir exatamente consigo mesma, a obra de arte enfim fornece a fonte mesma de seu poder crítico (EAGLETON, 1993, p. 253). Por isso, as imagens estéticas estão aí, não para mostrar a verdade dos objetos petrificados em seu momento de identidade, mas para dissuadir seu próprio momento de verdade.

Em oposição a uma racionalidade que domina e escraviza o mundo, essas imagens postulam o enfrentamento da obra para superar o possível "trauma" de perder lugar seguro na teoria. Por isso, para Adorno, uma teoria válida nos dias de hoje só pode ser aquela que tem a capacidade de pensar contra si mesma. De acordo com Tiburi,

[...] poder-se-ia dizer que a Teoria Estética - enquanto teoria que assume a consciência do recalque constitutivo de toda teoria - é aquela que assume a consequência desta realidade, pois é só através de uma problematização do fundo estético de toda teoria - a consciência de que há nela uma composição fundada no irracional e na matéria mais bruta que ela pode vir a ser autocrítica e crítica da racionalidade. A importância da arte para a autocrítica da teoria reside no fato de que esta seria a face denunciatória de uma injustiça feita à natureza e condensada na teoria e na racionalidade, que absolutiza o conceito e condena a verdade a um aparecer previamente estabelecido, oposto frontalmente ao aparecer da arte. (TIBURI, 2005, p. 200)

Conforme Tiburi (2003, p. 219), o desafio de Adorno seria muito mais o de compreender a arte como algo conceitual, ao pretender também esticar o conceito até experimentá-lo no limite da arte. A utopia do pensamento seria abrir o conceito ao não- 
conceitual, sem torná-los equivalentes. E, se o conceito deve ser poroso ao nãoconceitual, isso implica estender sua porosidade também às experiências artísticas.

Na experiência estética, a mistura de entusiasmo e reflexão, de emoção e análise racional das obras de arte pode tornar o sujeito consciente de sua condição reprimida pela razão dominadora, esclarecendo-o da limitação de sua identidade endurecida, sem que, com isso, tenha de se anular ou se dissolver como sujeito. Ao contrário, ainda que escapatória, há na experiência estética a possibilidade de uma expressividade do sujeito que não se apropriaria de modo imperioso do estranho e diferente, mas que nele encontra sua própria substância (ZAMORA, 2008, p. 220).

Do mesmo modo que a arte potencializa os esforços para escapar ao horror da objetificação, seu elemento expressivo também potencializa os aspectos formativos culturais da educação, em alguma medida, justamente por conta da potencialidade mimética inscrita na expressividade da obra de arte. Ao mesmo tempo, se sobressai a dimensão da sensibilidade e expressividade que a razão instrumental reprimiu em si mesma.

Ora, na estreita relação entre a arte e a sociedade, um dos principais elementos em que Adorno vislumbrava a possibilidade expressiva da arte é a estreita relação entre esta e a sociedade. Essa sua posição pode nos servir de fio condutor para a compreensão de suas complexas reflexões artístico-filosóficas e para tentar solucionar as aparentes dissonâncias entre sensibilidade e conceito. No entanto, para a arte, a tarefa não é simples, como também não nos conduz a uma pura resignação da própria obra, mas envolve uma elevada intenção da arte de preservar-se como obra de arte, no seu caráter temporal, histórico.

Dessa forma, se levamos em conta as produções artísticas, percebemos um movimento de interpretação e de reinvenção da própria vida e das possibilidades de uma educação formativa. Logo, o desenrolar de uma educação como experiência formativa requer reconhecer o sentido da expressividade da arte. 
O que temos então, com Adorno, é uma perspectiva enriquecedora para a experiência formativa. Poder-se-ia pensar, assim, na forma com que a arte reconstitui o que foi reprimido. De acordo com Adorno:

Aqui tem seu lugar a ideia (sic) da arte como reconstituição da natureza oprimida e implicada na dinâmica histórica; ela é verdadeiramente na arte um não-ente. Trata-se, para a arte, daquele outro para o qual a razão identificadora, que o reduziu a matéria, possui a palavra natureza. Este outro não é unidade e conceito, mas pluralidade [...]. Menos do que imitar a natureza, as obras de arte traduzem a sua transposição. Em última análise, deveria derrubar-se a doutrina da imitação; num sentido sublimado, a realidade deve imitar as obras de arte. (ADORNO, 1992, p. 152s.)

O estético converge com o formativo, uma vez que ambos implicam uma dinâmica não-restritiva do impulso mimético. Nos termos do pensamento adorniano, esse impulso advém da experiência autorreflexiva, no reconhecimento do impulso mimético da obra de arte. Essa experiência estética se registra na dificuldade de expressão do fenômeno, que advém do processo histórico da razão instrumental.

Se a experiência estética é de um "estremecimento" do eu que clama pelo nãoidêntico diante da natureza, a experiência formativa será, analogamente, a de uma destituição da segurança do eu, da razão dominadora. O que equivale a introduzir na formação cultural contemporânea a perspectiva de um estremecimento constitutivo do sujeito no processo educacional, um fundamento mimético para a experiência estética, mas também para a experiência formativa. 


\section{Considerações finais}

À educação, tendo em vista a expressividade estética das obras artísticas, o que importa é aquilo que ela revela (educare), ou seja, "a autorreflexão crítica" (ADORNO, 1995, p. 121). Referimo-nos, portanto, a uma educação crítica e autocrítica a ponto de perceber as armadilhas da racionalidade instrumentalizada, deste pensamento coisificado que nos enreda numa rede claustrofóbica.

Somente sob o signo da crítica imanente desse pensamento coisificado (isto é, da danificação da vida), alcançada pelo sujeito e por toda sociedade, estaria a possibilidade da libertação de ambos. Como a educação poderia contribuir para superar essa coisificação do pensamento? Sem dúvidas, o caminho não é o da conformação, mas, antes, o de constituir uma formação cultural da resistência crítica a partir do elemento expressivo da obra de arte.

O reconhecimento das possibilidades educativas da expressividade estética nos coloca uma missão espinhosa: combater os ícones da racionalidade instrumental da modernidade, ou seja, combater os mecanismos de poder que produzem pessoas capazes de cometer atos tão horrendos como os genocídios cometidos pelo nazismo. Isto é, aqueles atos que conseguiram matar de modo estritamente calculado, como as linhas férreas que conduziam os judeus aos campos de extermínio, que eram as mais rápidas e precisas da Alemanha na época do nazismo.

$\mathrm{Na}$ atualidade, ainda em nome da pretensa saída racional da crise do capitalismo, seria necessário construir a possibilidade de transformação das ações educativas em acontecimentos antibarbárie. A proposta da expressividade estética em Adorno requer o caminho da desbarbarização educacional. Exigência essa para além das simplificações do conceito de educação, de tal modo a possibilitar, no caminho de combate a própria barbárie, o resgate da autorreflexão nas práticas educativas. 


\section{Referências}

ADORNO, Theodor. Educação e emancipação. Tradução Wolfang Leo Maar. Rio de Janeiro: Paz e Terra, 1995.

ADORNO, Theodor. Textos escolhidos. São Paulo: Nova Cultural, 1999.

ADORNO, Theodor. Minima moralia. Tradução Luiz Eduardo Bicca. 2. ed. São Paulo: Ática, 1993.

ADORNO, Theodor. Teoria Estética. Tradução Artur Mourão. 1. ed. Lisboa: Edições 70, 1992.

ADORNO, Theodor. Teoria da Semicultura (Hallbildung). Tradução Newton Ramos de Oliveira, Bruno Pucci, Claúdia Moura Abreu. Educação e Sociedade. Campinas, n. 56, ano VXII, p. 388-411, dez. 1996.

ADORNO, Theodor; HORKHEIMER, Max. Dialética do esclarecimento: fragmentos filosóficos. Rio de Janeiro: Jorge Zahar Ed., 1985.

DUARTE, Rodrigo. Notas sobre modernidade e sujeito na Dialética do Esclarecimento. In: DUARTE, Rodrigo Adornos: nove ensaios sobre o filósofo frankfurtiano. Belo Horizonte: Ed. UFMG, 1997a. p. 45-63.

DUARTE, Rodrigo. Apuros do particular: uma leitura de Mínima Moralia. In: DUARTE, Rodrigo Adornos: nove ensaios sobre o filósofo frankfurtiano. Belo Horizonte: Ed. UFMG, 1997b (p.145-159).

EAGLETON, Terry. A ideologia da estética. Tradução Mauro Sá Rego Costa. Rio de Janeiro: Zahar, 1993.

GIACÓIA JR., Osvaldo. A ética na era da globalização à luz do pensamento de Adorno. In: LASTORIA, Luiz Antonio Calmon. Nabuco; COSTA, Belarmino Cesar Guimarães da; PUCCI, Bruno (Orgs.). Teoria crítica, ética e educação. Piracicaba/Campinas: Ed. UNIMEP/Ed. Autores Associados, 2001.

HORKHEIMER, Max. Eclipse da razão. Tradução Sebastião Uchoa Leite. São Paulo: Centauro, 2002.

JIMENEZ, Marc. Para ler Adorno. Rio de Janeiro: Francisco Alves, 1977.

MAAR, Wolfgang Leo. À guisa de introdução: Adorno e a experiência formativa. In: ADORNO, Theodor. Educação e Emancipação. Tradução Wolfang Leo Maar. Rio de Janeiro: Paz e Terra, 1995.

MAAR, Wolfgang Leo. Educação, sujeição e crítica na perspectiva de Adorno. In: DALBOSCO, Claudio. et al. Sobre filosofia e educação: subjetividade-intersubjetividade na fundamentação da práxis pedagógica. Passo Fundo: UPF, 2004. 
MARX, Karl. Manuscritos econômico-filosóficos. Lisboa: Edições 70, 1987.

TIBURI, Márcia. Metamorfose do conceito: ética e dialética negativa em Theodor Adorno. Porto Alegre: Editora da UFRGS, 2005.

TIBURI, Márcia. Uma outra história da razão e outros ensaios. São Leopoldo, RS: Editora da UNISINOS, 2003.

TÜRCKE, Christoph. Pronto-socorro para Adorno: fragmentos introdutórios a dialética negativa. In: ZUIN, Antonio Alvaro Souza.; PUCCI, B.; RAMOS-DE-OLIVEIRA, N. (Orgs.).

Ensaios frankfurtianos. São Paulo: Cortez, 2004. p. 41-59.

TÜRCKE, Christoph. O nascimento mítico do logos. In: DE BONI, Luis Alberto. (Org).

Finitude e transcendência: Festchrift em homenagem a Ernildo J. Stein. Petrópolis: Vozes, 1996. p. 81-90.

ZAMORA, José Antonio. Th. W. Adorno: pensar contra barbárie. São Leopoldo, RS: Nova Harmonia, 2008.

ZUIN, Antônio Álvaro Souza. Indústria cultural e educação: o novo canto da sereia. São Paulo: FAPESP e Autores Associados, 1999.

Recebido em: 21/03/2014 Aprovado em: 29/09/2014

Universidade do Estado de Santa Catarina - UDESC Programa de Pós-Graduação em Educação - PPGE

Revista Linhas

Volume 16 - Número 31 - Ano 2015 revistalinhas@gmail.com 